\title{
Design considerations for overdose education and Naloxone distribution: Results of a multi-stakeholder workshop
}

Katherine Sellen ( $\square$ ksellen@faculty.ocadu.ca )

OCAD University https://orcid.org/0000-0002-2434-7047

\section{Benjamin Markowitz}

Unity Health Toronto

Nick Goso

OCAD University

Alison Mulvale

OCAD University

Richard Hunt

OCAD University

Curtis Handford

Unity Health Toronto

Michelle Klaiman

Unity Health Toronto

Amy Wright

Toronto Public Health

Mercy Charles

Unity Health Toronto

Ruby Sniderman

Saint Michael Hospital: University Hospitals

Peter Jüni

Unity Health Toronto

Laurie Morrison

Unity Health Toronto

Douglas Campbell

University of Toronto

Pamela Leece

Public Health Ontario

Carol Strike

University of Toronto

Janet Parsons

University of Toronto

Aaron Orkin

University of Toronto

\section{Research}

Keywords: Opioid overdose, Overdose education, Harm reduction, Naloxone distribution, Stigma, Co-design 
Posted Date: November 15th, 2021

DOI: https://doi.org/10.21203/rs.3.rs-978690/v1

License: (c) (i) This work is licensed under a Creative Commons Attribution 4.0 International License. Read Full License 


\section{Abstract \\ Background}

Opioid overdose epidemic is a public health crisis that is impacting communities around the world. Overdose education and naloxone distribution programs equip and train lay people to respond in the event of an overdose. We aimed to design an open-access naloxone kit and ultra-brief education session for use in point-of-care settings.

\section{Methods}

We hosted a multi-stakeholder co-design workshop to elicit suggestions for the kit and education session. We recruited people with lived experience of opioid overdose, community representatives, and other stakeholders from family practice, emergency medicine, addictions medicine, and public health to participate in a one-day facilitated co-design discussion wherein large and small group discussions were audio-recorded, transcribed and analysed using thematic approaches.

\section{Results}

A total of twenty four participants participated in the multi-stakeholder workshop from five stakeholder groups including geographic and setting diversity. Collaborative dialogue and shared storytelling which revealed seven design considerations: recognizing overdose, how much naloxone, impact of stigma, legal risk of responding, position as conventional first aid, friends and family as responders, support to call 911.

\section{Conclusion}

To create an open access kit and ultra-brief education session for distribution in emergency departments, family practice and substance use treatment services, stigma is a central design consideration. Design choices that reference the iconography, type, and form of materials associated with first aid have the potential to satisfy the need to de-stigmatize overdose response.

\section{Introduction}

More than 17,602 apparent opioid-related deaths occurred in Canada between January 2016 and June 2020 [1]. While opioid agonist treatment is widely available in Canada and has been shown to reduce opioid overdoses, this crisis is escalating. It has worsened during the COVID-19 pandemic with evidence showing further increases in fatal and non-fatal overdoses $[2,3,4]$. Harm reduction services, crucial to the prevention of overdoses and other drug related harms, have been interrupted during the pandemic.

Overdose education and naloxone distribution (OEND) reduces opioid-related deaths by equipping and training people who are likely to witness overdose to respond with effective first aid interventions, including the administration of the opioid antagonist, naloxone $[5,6,7]$. OEND programs are among a small set of interventions that have been shown to reduce opioid-associated mortality at the population level [8]. While publicly-funded overdose education and naloxone distribution programs have been established in every province and territory in Canada [9], there remain gaps in our knowledge about effective design and implementation of these programs.

Take-home naloxone and training is a key component of OEND programs and provision of take-home naloxone and related education has been offered conventionally as part of harm reduction programs and addictions services [10]. Observational research of naloxone distribution and training programs suggest that lay people are highly capable of learning how to 
administer naloxone successfully [11]. For example, an observational study of overdoses in Massachusetts found a reduction in overdose mortality rates for communities that had implemented OEND programs versus those that had not [12].

Within Canada, the reclassification of naloxone to a non-prescription medication made it easier for community-members to get access to it $[13,14,15]$. Community pharmacies are key distribution points for take home naloxone in Canada and elsewhere $[16,17]$. Compared to the early 2000s, population wide studies in Canada reveal that naloxone has become more widely available across the country $[18,19]$ through pharmacy. In addition, community health centers and agencies offer naloxone kits and overdose response education free of charge. Despite these efforts, the Canadian opioid overdose epidemic is not yet slowing down [20] and has been exacerbated by the COVID-19 pandemic. Implementing the COVID-19 public health approaches to flatten epidemiological curve of pandemic have led to disruptions in harm reduction services, particularly at sites for Naloxone distribution [21]. This has led to the consideration of additional venues or situations in which OEND programs can be implemented wherever at-risk patients receive care. International guidelines call for naloxone distribution and overdose education among patients and communities at risk of or likely to witness opioid overdose, but there is still a lack supports to implement these guidelines [22, 23].

\subsection{Objectives}

The aim of this study is to explore how OEND programs be better designed especially for emergency departments, walk-in and family practices, and addiction medicine units. This study is part of the larger [removed for blind review] [removed for review] project [.

\section{Materials And Methods}

Using a co-design approach to frame the process and structure of the workshops, we used a qualitative methodology of interpretive description to approach the research questions [24] listed below. This inductive, constructivist approach was well-suited to the goals of the study as well as the principles of collaborative co-design [25].

\subsection{Study Design}

This engagement took the form of both participatory design methods $[26,27]$ as well as more discrete co-design techniques $[28,29]$. The workshop included both organizational perspectives as well as the perspectives of those with lived experience of overdose and overdose response over 1 day of facilitated co-design activities. The questions guiding the structure of the workshop were deliberating open ended to elicit insights on general factors relevant to opioid overdose response and OEND programs:

1. What are the characteristics and concerns of stakeholders in relation to opioid overdose?

2. What is the current experience of overdose in terms of awareness, access, and administration of naloxone?

3. How might stakeholders envision a better experience in terms of awareness, access, and administration of naloxone?

Participants in the workshops were supported using standard co-design materials (empathy maps, and experience maps) $[30,31]$ customized to reflect the questions above with facilitation by co-design specialists from [removed for review] [32, 33].

\subsection{Setting}

The workshop was hosted by the [removed for review] project at the [removed for veiew], with support from the [removed for review]. Ethics approval for the study was granted by both the relevant healthcare partners and academic partners including the Research Ethics Boards of [removed for blind review] and [removed for review]. 


\subsection{Sampling and Recruitment}

The participants were recruited from the pan-Canadian [removed for review] for the [removed for review] project. People with lived experience of drug use and overdose were invited by the [removed for review] and nominated by [removed for review] community partners. Each table consisted of between three and five representatives, supported by three circulating research team members and a lead facilitator.

\subsection{Data Collection}

The workshops were supported by access to and use of a variety of abstract materials and resources (sticky notes, pens, stickers, prompt cards). The visible results of the workshop (i.e., work done on paper/maps) were recorded photographically. During the co-design workshop dialogue at each of five tables (each representing a unique stakeholder perspective) was audio-recorded to capture discussions on the lived experiences of those stakeholder roles. A professional transcriptionist transcribed each audio recording to capture conversations in a form as close to the original oral style as possible.

\subsection{Analysis}

As researchers interested in the field of opioid overdose, we were aware of the stigma experienced by people who use opioids [36]. As qualitative researchers, we employed stigma theory to guide study design and analysis [37]. Specifically, we drew on Link and Phelan's work, recognizing stigma is enacted the level of the individual and social relations and structural/systemic levels [38]. We took an inductive, qualitative approach [39] to analyze transcripts. Analysis was an iterative process, in which we were forming and refining 'themes' [35]. Initially, two senior members of the research team ([removed for review]), experts in qualitative research) reviewed and analyzed a subset of the transcripts to identify initial codes and patterns, developing a preliminary coding framework [36]. A third qualitative analyst joined the team (([removed for review]) and worked closely with the senior analysts to apply the coding framework. During this refinement process, there was subsequent input from a fourth analyst (([removed for review]) who was well versed in policy and public health practice in the realm of opioid overdose [37]. Over the course of analysis, we formed a list of questions (Table 1) that corresponded to the content of discussions, refining text related to this line of questioning into core themes that further characterized the dialogue. Dye has described [38], this approach resembles a "kaleidoscope". The goal of this analysis was to highlight key elements of the first-hand knowledge sharing that took place amongst the participating stakeholders.

Table 1

Analytic questions framed according to what participants were discussing

\begin{tabular}{|c|c|}
\hline Naloxone & Opioid Overdose \\
\hline \multirow{2}{*}{$\begin{array}{l}\text { - Who should be distributing naloxone and } \\
\text { training lay users? }\end{array}$} & -Who is at risk? \\
\hline & -Who needs overdose response preparation? \\
\hline -What are barriers to distribution? & -What does an overdose look like? \\
\hline $\begin{array}{l}\text { - Why is naloxone not like other more } \\
\text { mainstream medications? }\end{array}$ & -What are barriers to responding? \\
\hline - How should naloxone be distributed? & -Where do overdoses occur? \\
\hline - How much naloxone is enough? & -Why do people not intervene? \\
\hline - How is naloxone being administered? & -Why do people overdose? \\
\hline \multirow[t]{3}{*}{-When naloxone is used, what ensues? } & -Why is the overdose landscape changing? \\
\hline & $\begin{array}{l}\text { - How does the general public characterize opioid overdose? How do } \\
\text { healthcare providers characterize it? }\end{array}$ \\
\hline & - How is overdose care and education provided? \\
\hline
\end{tabular}




\section{Results}

In total, 24 people participated in the workshop in stakeholder groupings including 'family/friends of those at risk of overdose', 'emergency responders', 'people who take opioids', 'frontline/harm reduction or clinical and allied health practitioners', and 'program administration'. At points throughout the results, we delineate who is talking according to the following perspectives: persons who take opioids (PWTO), family/friends of PWTO, emergency medical services (EMS), law enforcement, providers (physicians, nurses, nurse practitioners and pharmacists), and harm reduction workers.

The results of an analysis of their dialogue and participation indicated three themes covering naloxone administration and specific needs of response, training materials, and kits; issues of access, and issues of awareness to include stigma and public perception and support for naloxone programs.

\subsection{Are community members (professional and lay) prepared to respond?}

Participants questioned whether community members (including police officers, service providers and lay people) are prepared to respond to opioid overdose in real-time situations. In particular, participants voiced concerns related to the following topics: recognizing the physical signs of an overdose, knowing how much naloxone is enough, first-aid response, legal barriers and overdose risk perceptions.

What does opioid overdose look like?

'What overdose looks like' had two aspects that participants emphasized - one had to do with recognizing the signs of overdose (and what to watch for) and the other had to do with stigma associated with the circumstances in which overdose occurs. Participants expressed concerns that lay people along with service professionals (police officers or security guards in particular) may experience difficulties recognizing an opioid overdose when they encounter it in a community setting. A harm reduction worker noted that 'mixed' or 'atypical presentations can challenge responders' preconceived notions of what overdose looks like. Similarly, discussions at the family/friends table, corroborated that opioid overdoses can be difficult to recognize:

Family/friend of PWTO: ... some of the overdoses have an odd presentation as well, because now we're getting the fentanyl and carfentanil [mixed] in the crystal meth,...

Family and friends of PWTO worried that stigma and contextual factors may interfere with recognizing and responding to an overdose, potentially amplifying reluctance to respond. They portrayed overdose as disordered and used stigmatising terms to describe it, having the potential to be a "messy or dirty scene" with many distractions (e.g., the smell of alcohol, the presence of needles, and the sight of vomit), which could deter first-responders from acting, or acting in a timely way. They described this as manifested in reluctance to touch someone in overdose, if drug paraphernalia are present, for example:

Family/friend of PWTO: If there's education around what an overdose looks like, that's a good thing, but it still contributes to the stigma. Because, if somebody has vomit around them, nobody's going to touch them. If somebody has syringes on them, nobody's going to touch them.

From this perspective, the physical nature of what overdose looks like can be a deterrent to timely first-response.

How much naloxone is enough?

With respect to administering naloxone, participants raised questions as to how much naloxone is enough to counter the potent effects of synthetic opioids like carfentanil. A harm reduction worker recounted:

Page 6/18 
When you're talking about the new synthetic opioids, like, we're now carrying six vials with us. And, even with that, we had an incident a couple of weeks ago where the nurse I was with went through all six.

Moreover, the form in which naloxone is administered may influence one's perception of dose response. In particular, a PWTO voiced skepticism over nasal naloxone, and if it was as effective as injection,

... when you overdose, your breathing [is] shallow, you know what I mean. So, if you can't take a breath in, is the spray going to do anything, right?

Ongoing work needs to be done to provide opportunities to address questions about naloxone use and how it works. Opposite to these concerns about not giving enough naloxone, participants also discussed the notion of withdrawal associated with administering too much naloxone. They worried that by giving too much naloxone all at once, a first responder might be abruptly putting the overdose victim into a state of withdrawal. For example:

Family/friend of PWTO: ... once people are overdosed, when they come to after the naloxone, they're very agitated. They have pain, they're angry and they get instant withdrawal. So, learning how to deal with somebody after they come out of an overdose and what we can do ...

Participant accounts related to this issue of withdrawal suggest that administering naloxone may be conceptualized as a balancing act. On the one hand, not being equipped with enough naloxone to resuscitate an individual was a fear recounted by participants. A harm reduction worker recounted their approach to this issue:

I think the other thing that we try and get across is, use one dose and see what happens. Don't panic and give all three doses because otherwise you end up putting somebody into withdrawal and they're not happy. So, it's almost like titrating. Give one dose, carry on with your resuscitation and then give another dose.

\section{Resuscitation and feeling prepared}

Aside from administering naloxone, participants spoke about a broader first-aid response. The notion of feeling prepared was important to lay participants, as PWTO and their family/friends wanted to empower themselves with the necessary first-aid knowledge and skills to effectively respond in an overdose situation. This involved learning how to take command of (or "quarterback") the situation:

Family/friend of PWTO: So, if you're there and you're the quarterback, you can, kind of, like do the playback for that. 'Hi, I'm [name]... I have experience with this, I'm going to take control of the situation right now. Would you please go [call] 911 and call paramedics for us? ...

Similar to having a fire safety plan in one's home, family and friends spoke about a desire to implement opioid overdose safety plans as common practice within communities:

Family/friend: if you have a Fire plan for your house, why not have an overdose plan? You're in charge of calling. You've got to get the kit. You're staying with the person. Something like that?

To help guide lay responders to prepare for resuscitation, healthcare providers spoke about developing their own overdose response instructions to accompany the naloxone kits they were distributing:

Provider: This is something we made up for our kits'... So, you do, 'shake and shout'... if you don't get a response, then you call 911. Then, you administer naloxone. Then, you check breathing. If they're not breathing, then you do chest compressions for two minutes, then administer a second dose. 
Although healthcare providers spoke about trying to educate lay people, participants reflected upon some uncertainties they recognized in the context of overdose resuscitation. An EMS participant noted,

EMS participant: ... we're just sort of questioning what is the best sort of chain of survival for this person? And, it's beyond just that, but is it call 911 first? Is [it] deliver Naloxone first? Is it start ventilations? If that's the case then we need to start properly training people...

There were broader resuscitation principles that applied to this first-aid event. In addition, prior to the moment when an individual enters into overdose, a family/friend of PWTO indicated that it was also critical to acknowledge a "using plan" as a preventive component of the broad domain of overdose education,

Family/friend: I was just talking to the Chief [Indigenous community]... and he told me, the people that died of the carfentanil recently... were from his reserve...And he said, "I don't know why they didn't have someone try it out first instead of all of them doing it." ... he said they should have a plan before they're going to use if they don't know who they're buying those drugs from, right? ...

Rather than contextualize overdose education and naloxone distribution programs solely around the acute episode of overdose (i.e. when a person requires resuscitation), this quote suggests that public health initiatives could benefit from widening their scope and acknowledging the events leading up to an overdose. This preparatory mechanism to avoid overdose seemed especially valuable as participants highlighted barriers to calling 911 (as presented in the next section).

Barriers to calling 911

Participants indicated that calling 911 is an integral part of an overdose response within a community setting. Layperson accounts highlighted a lack of trust between police officers and some community members, as people might fear that police officers could press drug-related charges against them at an overdose scene, even for carrying naloxone. As PWTO recounted:

I almost got arrested because of my naloxone kit. None of them [police] knew what it was. None of them knew anything about it... we have people that, because of the stigma of law enforcement, they administer Narcan, don't tell anybody and leave.

Feeling a need to flee the scene after calling 911 and perceiving themselves to be at legal risk when providing a potentially life-saving intervention (despite the Good Samaritan Act) makes this aspect of designing overdose education interventions particularly difficult.

For lay participants who spoke about calling 911, they shared their own approaches regarding how to communicate an overdose situation to the call center,

Family/friend of PWTO: ... do not say that they overdosed. Just say, 'my friend is not breathing.' Because, chances are, the ambulance may not call the cops unless they see, you know, like, a horrific scene, right?."'

Upon hearing these accounts related to fear of police accompanying EMS to overdose scenes, a representative of law enforcement explained why police were needed at the scene,

Law enforcement: It has nothing to do with the criminal aspect. It's for provider safety, right. So, that to me is very powerful, you know, people that aren't saying it's an overdose just because they think there's gonna be a legal ramification and that's putting responders into an unsafe position.

Although members of law enforcement may see police presence as helpful in ensuring safety for first responders, other participants spoke about their presence as intimidating for PWTO. To combat fears concerning law enforcement, a 
healthcare provider spoke about adapting their educational approach to account for the broader legal context influencing how lay people respond, which they considered an additional burden for providers and harm reduction workers.

Provider:...if you call in and you're in an apartment with a lot of drug paraphernalia, you drag that patient out...the person out into the hallway, you lock your door and you do your first aid there until EMS arrives, and then you leave. ....sort of like a temporary measure until law enforcement really puts in the effort to build a trusting relationship with the community .."

Participants in this study indicated that legal concerns and stigma need accounting for when thinking about how to implement overdose response training into communities, perhaps more so than in other situations where they might call emergency services.

\section{Overdose risk perceptions}

Although participants across tables generally implied that there was a "typical" individual at risk for overdose (i.e. people on high-dose opioid prescriptions or who inject drugs), participants emphasized that naloxone administration and overdose response should be viewed as a broader community health concern, one that could impact anybody using drugs or taking prescription opioids. For instance, there was talk amongst law enforcement participants about overdoses that affect opioid-naïve individuals, such as those who are using illicit recreational drugs tainted with synthetic opioids.

EMS/law enforcement: So, for an example, in British Columbia, everybody and their dog focuses on the Downtown Eastside, but in reality, these issues are anywhere there's a drug element, right? And, that started with cocaine. So, anywhere there was cocaine ... that didn't get the attention [it] needed.

Moreover, a provider proclaimed that the general public should widen their scope when thinking about who needs naloxone,

...there's no one population. It's across the spectrum of gender. It's across the spectrum of income levels. It's across race, ethnicity. So, it's not just low-income individuals who are mostly suffering from overdose. But, you have, like, Bay Street professionals who have just as much risk for addiction.

Although providers felt able to identify patients at risk for overdose, they felt that convincing individual patients of this risk was a difficult endeavor,

Provider: I have a lot of patients who will have high-dose prescribing and benzodiazepine and, in my view, be at really high risk because of what we know from research. But, they don't feel like they're at risk because they've never overdosed before because their doctor is prescribing it. ...

I'm sure a lot of it relates to stigma that, 'I'm not that person who's going to overdose.'

Broadening the scope of who is actually at risk of overdose and recognizing the opioid crisis for the public health emergency that it is seems vital to designing an effective educational intervention that[6] does not feed into stigmatizing views or attitudes surrounding those who overdose.

\subsection{Moving naloxone out of the professional sphere}

Within discussions, participants conveyed a desire to make naloxone a community-based resource; accessed by community members to use in a timely fashion to save a peer's life. Participants expressed that naloxone should be readily accessible to a broad range of people. As one harm reduction worker explained,

It should be the people for the people. We shouldn't be delineating, you know, pharmacists are the one[s] that should be delivering this. It should be people for people and .. 
Unlike other first aid interventions such as public access to automatic external defibrillators (AED), participants described that naloxone was not yet normalized within communities. For instance, a PWTO said,

...you can't get naloxone unless you say you're an addict. Or, supporting an addict and then the addict has to come with you. Like I think that it should be available to whoever wants it.

In addition to participants with lived experience, providers likewise expressed concern that naloxone was not easily available in public spaces where overdoses (similar to heart attacks) have occurred, such as restaurants or coffee shops,

Provider: Well, I mean you could even go as far as having it like an AED, right? We have it [AED] all in community centres. Why don't we have naloxone boxes that you could put beside your AED, with training? Or parks, or anywhere. Or, downtown Toronto on Yonge Street, you know? Anywhere.

Participants discussed how accessing naloxone could be difficult for individuals due to the centralized nature of distribution via pharmacies. Providers discussed an alternative approach of peer distribution as a means to make naloxone more readily accessible to those at risk for overdose,

Provider: Another issue that we've seen that you just made me think of, was being able to train peers or people who are users and live in buildings where there's high use, to be able to teach them, like, have the certification, the requirements, the authorization if you will, like, from a particular organization to distribute naloxone. ... So, I think peer distribution of naloxone is huge.

Furthermore, jurisdiction could ultimately dictate how readily available (and accessible) naloxone is. Taking Ontario as an example, a provider indicated that there are northern regions of the province with relatively few pharmacies per capita, yet these communities have a disproportionately high concentration of individuals at risk for overdose,

Provider: ... we are hit really hard by opiate addiction. So, there has to be a way of rolling out naloxone. And, we use what we call 'unregulated care providers' to deliver our Suboxone programs...So, we actually train what we would call 'lay people' to be able to do medical things....

Participants emphasized that community-based (or peer) distribution of naloxone should be an essential component of intervention design, as it would help naloxone branch out more effectively from the professional sphere (such as pharmacies) and allow it to become a more readily accessible first-aid medication for lay-users.

\subsection{Narrative around naloxone}

In discussions, professional and lay views coalesced, which helped develop a broader understanding of what the overarching public narrative is like surrounding naloxone. Notably, what seemed to hinder the wide-spread uptake of naloxone within community settings was stigma, whereby naloxone is commonly associated with injection drug use, and PWTO are prone to encounter negative perceptions of others. For example, a person with lived experience believed that naloxone would only start to become more widely accepted and respected if it played to the hearts of Canadians (appealing to empathy) and was seen as a life-saving medication that could be used to save someone you love,

... when that young woman... a couple years ago died, then everybody was talking about Naloxone, right? And, that's when you hear about naloxone...

This "young woman" portrayed above is described as an unlikely victim of overdose. The participant presents them as someone who the public would not normally expect as needing naloxone. Contrary to this "young woman", a provider participant painted a different picture in their account of what appear to be 'repeat offenders' who health care providers can lose compassion for, 
Provider: We definitely see the stigma associated with it even within our own practice. 'This is not our job.' 'We don't have time to deal with this.' 'This is your 'get out of jail free card.' 'This promotes drug use.' We hear this and we see this in our practice. So, there's blaming and shaming with individuals who use.

Furthermore, providers spoke about difficulties generating public support for naloxone and harm reduction programming in contrast to public acceptance of governments other major safety concerns,

Provider: When you think of all the funding and public service announcements that go into car safety; seatbelts, roads, traffic, all the money that goes into keeping us safe on the road. ...But, we can't accept that people are going to continue using [opioids]. They're not just going to stop, so how do we figure that out? It's a massive problem.

The core goal of using naloxone is to save a person's life, yet participants indicated that an abstinence narrative had detracted attention away from accomplishing this fundamental goal:

Person with lived experience: ... it's that fear of, if I'm using by myself and I OD what do I do, you know? That's a big fear. So, yeah. Especially when you've been clean and you know your family and friends know that you've been clean, you don't want to phone them up and say 'I'm going to use, can you call me in half an hour and make sure I'm okay?'...

Here we see that PWTO do not always feel comfortable opening up to others (especially family members) about their drug use practices, and subsequently, use alone. Alternatively, some PWTO may take a more advocative stance against an abstinence narrative and actively try to make naloxone readily available for people injecting opioids,

Person with lived experience: She [girlfriend] was the best advocate, you know. She was such an advocate for it, you know like every time that we used together, we'd always say, 'hey I've got a kit' and she'd be like, 'yep I've got one too.'

As described above, this participant perceived social relationships and interactions as critical in terms of the uptake of naloxone within the context of taking opioids. This points to the value of supporting social relationships and ties for OEND programs.

More directly, the results indicate a variety of design considerations for OEND (Table 2) that can be summarized as follows: 
Table 2

Design Considerations and Requirements for OEND toolkit

Considerations Design requirements

1. Recognizing an overdose may not be straight forward • • Training should support rapid response,

- Include messaging that naloxone is safe to use in any unresponsive person, and will not cause any harm

2. Responders may not know "how much is enough"

- The kit should be designed so that the responder does not need to make dosing decisions

3. Stigma may reduce the likelihood and pace of response as well as the likelihood of asking for, giving out, and accepting the offer of a kit and training

- An anti-stigma approach in aesthetic choices, language use, and tone, is necessary to reduce potential barriers to response

- The choice of nasal naloxone in take home naloxone distribution kits is suggested to reduce stigma, reduce potential training requirements, and increase likelihood of timely response

4. drug paraphernalia may be both stigmatizing and a potential legal risk to lay responders

- The choice of nasal naloxone in take home naloxone distribution kits is suggested to increase uptake among individuals who may be deterred by needles and ampoules

5. There is a need to move overdose training and response beyond the professional sphere and beyond those

- Design choices should position overdose response immediately at risk who may already be responding and comfortable with needle-based naloxone

6. There is high potential for overdose alone and there is a need to support the option of response by a friend or family member as a conventional first aid intervention,

7. Calling 911 may be thought of as not a "safe" option for those that use drugs and their family and friends

- The design needs to support sharing with others (both training and kit), recognition as a first aid supply, positioning the kit as part of a safety plan

- The training kit should emphasize calling 911, but also support response where 911 is not called.

\section{Discussion}

The results from the work described in this paper led to insights informing the design of an integrated solution for an OEND program combining elements across digital and physical media for use in family practice, emergency departments, addictions clinics and community settings [34]. The multi-stakeholder perspectives on OEND detailed here reveal important features to be considered when designing an educational intervention tailored to lay bystanders responding to opioid overdose. One of the key merits of our study is that it brought together a wide range of relevant stakeholders to share their expertise, experiences and perspectives. Workshop attendees spoke to community members' preparedness to respond to opioid overdose in terms of: lay responders' capacity to recognize an overdose; naloxone distribution was characterized as only one part of a more complex resuscitation response, which included preventative strategies; perceived legal ramifications and risks associated with calling 911; as well as the role stigma plays in responders' willingness to intervene.

Participants commented on access to naloxone as a major concern, whereby some saw an over-reliance on pharmacies for dispensing as problematic, which confirms existing research [17]. The issue of access is further compounded in more remote communities where pharmacies themselves can be scarce. Several barriers preventing communities from having equal access to naloxone and overdose education identified in existing literature [9] were confirmed by participants. These barriers reflect the need for a holistic approach to OEND programming that addresses the complexity of stigma and how it is experienced on an individual level by understanding the larger social, political and legal system surrounding drug use 
[16]. Participants recounted how the stigma surrounding opioid use extended to naloxone as an intervention, differentiating it from how (for example) AED or Epi-Pens are perceived. Abstinence discourses [39] were seen as a barrier to naloxone uptake, in that carrying naloxone implied illicit opioid use. Participants noted that opioid addiction and the need for naloxone extends across all sectors of society, and that normalizing naloxone use will facilitate uptake.

Stigma theory $[40,41]$ informed our analytic approach to this dataset. Recognizing the role stigma plays as it relates to the ongoing opioid crisis is of critical importance when it comes to intervention design. As Link and Phelan [41] noted almost 20 years ago, "stigmatization probably has a dramatic bearing on the distribution of life chances in such areas as earnings, housing, criminal involvement, health and even life itself." This study reinforces existing work on stigma rather than uncovering new ideas about stigma. We chose to focus on how the discussions on stigma illuminated key features to consider in relation to designing an OEND intervention. Unfortunately, a predominant narrative [42] surrounding PWTO as 'addicts' persists in Canadian society [36]. This workshop highlighted that the pervasive stigma surrounding opioid use and opioid overdose remains a significant barrier to the uptake of both naloxone kits and overdose resuscitation efforts. A clear message emerged from the workshop: the integration of an anti-stigma approach in both the design process and the design choices is necessary in attempting to address the social and political context of the opioid crisis.

Addressing the issue of broadening naloxone awareness and access, participants discussed how patients taking opioids may believe that there is a certain 'type' of person at risk for overdose, and that because they do not identify as a person 'at risk' they may be reluctant to accept naloxone. In combination, this implies attention needs to be paid to specific design choices that acknowledge and resist attributes that indicate either marginalisation or mainstreaming. In turn, this would position the design as an opportunity for shifting the narrative on overdose, whilst being supportive of a harm reduction approach. This response is further complicated by concerns about legal ramifications of calling 911 . Finally, broadening the scope of who is actually at risk of overdose and recognizing the opioid crisis for the public health emergency that it is is vital to designing an effective educational intervention.

OEND programs were launched across the country at a rate that has made it difficult to evaluate individual quality and implementation, and compare effectiveness, making an assessment of equitable naloxone distribution infeasible [9]. Very little work exists to help guide the detailed design of materials to support OEND, the exception being a recent study from the Food and Drug Administration (FDA) in the USA on product labelling to educate lay people on steps to follow for effective administration of naloxone [17]. OEND initiatives such as that described by the FDA are meant to strengthen lay person capacity to successfully administer. Before an individual even sees a label, it is vital that programs exist to get naloxone into the hands of those who are in situations to use it.

To meet the goals of the project to create a kit and training that supports overdose response among a broader public through broad point of care access, this work highlights the need to address stigma as central to the design process and outcome. Design choices must broadly move naloxone, overdose, and overdose first aid beyond aesthetics and language that would connect to negative concepts. Design choices that reference the iconography, type, and form of materials associated with first aid have the potential to satisfy the need to de-stigmatize overdose response. In order to design effectively in a context of specific tensions and stigma, a co-design approach is appropriate, including the continuous engagement of both community members and staff in the point of care settings where OEND is proposed. Moving beyond the design process and evaluation of the OEND kit and training, the results suggest a high need for translation of the work of this project through public engagement and knowledge mobilization activities.

\subsection{Limitations}

It is important to note that the context was urban Toronto in terms of lived/living experience representatives, while paramedics, program directors, police officers, allied health were not exclusively working in Toronto. There was significant representation from Vancouver whose experience of the overdose crisis was more longstanding. We were fortunate to have

Page $13 / 18$ 
participants who were able to bring perspectives from other jurisdictions, remote communities, Indigenous communities, western Canada, recognizing that the local urban context dominated the discussion but that there are commonalities across jurisdictions. Naloxone suppliers were not represented at the workshop.

\section{Conclusion}

OEND kits emerged from specific communities at risk of opioid overdose, and in the context of specific tensions and stigma. These political and social messages and factors are embedded in and enacted through conventional kit designs. The programs created for overcoming and redressing stigma and the harmful effects of criminalizing people who use drugs might be accomplished in part through the deliberate redesign and co-design of the technologies used to address the crisis - an effort to effectively "design away" some of the more insidious political messages embedded in the technologies used to address the crisis. In this study we have been able to elucidate seven design considerations with actionable design requirements for detailed kit and training design including those that address stigma more directly. While stigma was not the primary focus of the research, it is a pervasive factor in naloxone awareness, access and overdose response.

\section{Abbreviations}

OEND: Opioid overdose education and naloxone distribution

COVID-19: Coronavirus disease 2019

[removed for review]

[removed for review]

PWTO: Person who take opioids

EMS: Emergency medical services

OD: Overdose

OD'd: Overdosed

AED: Automated external defibrillator

FDA: Food and Drug Administration

\section{Declarations}

\section{Author Contributions:}

*This author designed the study including the co-design materials and process, analysis, interpretation of results and manuscript writing

9 These authors contributed equally to this work leading the analysis and draft results and discussion, and writing the draft manuscript

\& These authors also contributed equally to this work though the design of co-design materials and identification of design insights

${ }^{\wedge}$ These authors provided manuscript review, manuscript editing, and contributing references 
a These authors contributed to recruitment, ethics materials, manuscript review, and study administration.

\section{Ethics approval and consent to participate}

Ethics approval for the study was granted by both the relevant healthcare partners and academic partners including the Research Ethics Boards of OCAD University (\# and Unity Health (\#17-037).

\section{Consent for publication}

No participant information is included.

\section{Data Availability Statement}

Data available on request due to privacy/ethical restrictions

\section{Competing interests}

Aaron Orkin: Member of the American Red Cross Scientific Advisory Committee, First Aid Subcouncil; Member of the International Liaison Committee on Resuscitation First Aid Task Force; Expert Witness for the Office of the Chief Coroner of Ontario regarding an inquest into the prehospital death of a person experiencing opioid overdose.

Curtis Handford: Funded Primary Care Clinical Lead position mid-east Toronto sub-region of Toronto Central Local Health Integration Network; also funded position of Deputy Chief, Department of Family and Community Medicine.

Peter Jüni: Received research grants to the institution from Appili Therapeutics, Astra Zeneca, Biotronik, Biosensors International, Eli Lilly, The Medicines Company, and honoraria to the institution for participation in advisory boards and/or consulting from Amgen, Ava and Fresenius. Serve as an unpaid member of the steering group or executive committee of trials funded by Abbott Vascular, Astra Zeneca, Biotronik, Biosensors, St. Jude Medical, Terumo and The Medicines Company.

Pamela Leece: Collaborator on Canadian Institutes of Health Research-funded evaluation of the Ontario naloxone program and pharmacy naloxone program, and Canadian Research Initiative in Substance Misuse, Naloxone Best Practices group.

All other authors declared no conflicts of interest.

\section{Funding}

This project was funded by a project grant from the Canadian Institutes of Health Research (CIHR) grant \#148817 and Canadian Research Initiative in Substance Misuse. The Canadian Centre on Substance Use and Addiction (CCSA) also contributed to project workshops and community engagement.

\section{Acknowledgements}

The investigators are particularly grateful to the SOONER Community Advisory Committee for their engagement and direction on this project. Thank you to Toronto Public Health and the staff and volunteers at The Works for their contributions, and to the staff at the Li Ka Shing Knowledge Institute, St. Michael's Hospital, for supporting research ethics and participant processes. The SOONER Investigators acknowledge Ruby Sniderman and Audra Stitt for their contributions to administration and coordination. We acknowledge Adapt Pharmaceuticals for providing intranasal naloxone devices.

\section{References}


1. Public Health Agency of Canada. Opioid- and Stimulant-related Harms in Canada [Internet]. Canada.ca. 2020 [cited 2021 Jan 7]. Available from: https://health-infobase.canada.ca/substance-related-harms/opioids-stimulants/

2. Ontario Drug Policy Research Network. A report prepared by: The Ontario Drug Policy Research Network Public Health Ontario Centre on Drug Policy Evaluation [Internet].; 2020 Nov [cited 2021 Jan 15] p. 1-24. Available from:

https://www.publichealthontario.ca/-/media/documents/o/2020/opioid-mortality-covid-surveillance-report.pdf?la=en

3. Rodda LN, West KL, LeSaint KT. Opioid Overdose-Related Emergency Department Visits and Accidental Deaths during the COVID-19 Pandemic. Journal of Urban Health [Internet]. 2020 Sep 28 [cited 2021 Mar 15];97(6):808-13. Available from: https://link.springer.com/article/10.1007/s11524-020-00486-y

4. Wilkinson R, Hines L, Holland A, Mandal S, Phipps E. Rapid evidence review of harm reduction interventions and messaging for people who inject drugs during pandemic events: implications for the ongoing COVID-19 response. Harm Reduction Journal [Internet]. 2020 Dec [cited 2021 Mar 15];17(1). Available from:

https://harmreductionjournal.biomedcentral.com/articles/10.1186/s12954-020-00445-5

5. Haley DF, Saitz R. The Opioid Epidemic During the COVID-19 Pandemic. JAMA [Internet]. 2020 Oct 27 [cited 2021 Mar 15];324(16):1615. Available from: https://jamanetwork.com/journals/jama/article-abstract/2770985

6. Walley AY, Xuan Z, Hackman HH, Quinn E, Doe-Simkins M, Sorensen-Alawad A, et al. Opioid overdose rates and implementation of overdose education and nasal naloxone distribution in Massachusetts: interrupted time series analysis. BMJ [Internet]. 2013 Jan 30 [cited 2021 Jan 7];346(jan30 5):f174-4. Available from:

https://www.bmj.com/content/346/bmj.f174

7. Irvine MA, Buxton JA, Otterstatter M, Balshaw R, Gustafson R, Tyndall M, et al. Distribution of take-home opioid antagonist kits during a synthetic opioid epidemic in British Columbia, Canada: a modelling study. The Lancet Public Health [Internet]. 2018 May [cited 2021 Jan 7];3(5):e218-25. Available from:

https://www.thelancet.com/journals/lanpub/article/PIIS2468-2667(18)30044-6/fulltext

8. McDonald R, Strang J. Are take-home naloxone programmes effective? Systematic review utilizing application of the Bradford Hill criteria. Addiction [Internet]. 2016 Mar 30 [cited 2021 Mar 15];111(7):1177-87. Available from:

https://onlinelibrary.wiley.com/doi/full/10.1111/add.13326

9. Naloxone Distribution Environmental Scan [Internet]. CRISM. 2019 [cited 2021 Jan 7]. Available from:

https://crism.ca/2019/06/13/naloxone-distribution-environmental-scan/

10. United Nations Office on Drugs and Crime. Opioid overdose: preventing and reducing opioid overdose mortality [Internet]. 2013. Available from: https://www.unodc.org/docs/treatment/overdose.pdf

11. Opioid Overdose Prevention Programs Providing Naloxone to Laypersons - United States, 2014 [Internet]. 2021 [cited 2021 Jan 7]. Available from: https://www.cdc.gov/mmwr/preview/mmwrhtml/mm6423a2.htm

12. Walley AY, Doe-Simkins M, Quinn E, Pierce C, Xuan Z, Ozonoff A. Opioid overdose prevention with intranasal naloxone among people who take methadone. Journal of Substance Abuse Treatment [Internet]. 2013 Feb [cited 2021 Jan 7];44(2):241-7. Available from: https://pubmed.ncbi.nlm.nih.gov/22980450/

13. Health Canada. Federal actions on opioids to Date - Canada.ca [Internet]. Canada.ca. 2020 [cited 2021 Jan 7]. Available from: https://www.canada.ca/en/health-canada/services/substance-use/problematic-prescription-druguse/opioids/federal-actions/overview.html

14. Health Canada. Notice: Prescription Drug List (PDL): Naloxone - Canada.ca [Internet]. Canada.ca. 2016 [cited 2021 Jan 7]. Available from: https://www.canada.ca/en/health-canada/services/drugs-health-products/drugproducts/prescription-drug-list/notice-naloxone.html

15. Strike C, Watson TM. Losing the uphill battle? Emergent harm reduction interventions and barriers during the opioid overdose crisis in Canada. International Journal of Drug Policy. 2019 Apr;1(71).

16. Farrugia A, Fraser S, Dwyer R. Assembling the Social and Political Dimensions of Take-Home Naloxone. Contemporary Drug Problems [Internet]. 2017 Aug 4 [cited 2021 Jan 7];44(3):163-75. Available from:

Page $16 / 18$ 
https://journals.sagepub.com/doi/full/10.1177/0091450917723350

17. Cohen BR, Mahoney KM, Baro E, Squire C, Beck M, Travis S, et al. FDA Initiative for Drug Facts Label for Over-theCounter Naloxone. New England Journal of Medicine [Internet]. 2020 May 28 [cited 2021 Jan 7];382(22):2129-36. Available from: https://www.nejm.org/doi/full/10.1056/NEJMsa1912403\#article_citing_articles

18. Cressman AM, Mazereeuw G, Guan Q, Jia W, Gomes T, Juurlink DN. Availability of naloxone in Canadian pharmacies:a population-based survey. CMAJ Open [Internet]. 2017 Nov 8 [cited 2021 Jan 7];5(4):E779-84. Available from: http://cmajopen.ca/content/5/4/E779.full

19. Antoniou T, McCormack D, Campbell T, Sutradhar R, Tadrous M, Lum-Wilson N, et al. Geographic variation in the provision of naloxone by pharmacies in Ontario, Canada: A population-based small area variation analysis. Drug and Alcohol Dependence [Internet]. 2020 Nov [cited 2021 Jan 7];216:108238. Available from: https://www.sciencedirect.com/science/article/pii/S0376871620304038?via\%3Dihub

20. Health Canada. Measuring the impact of the opioid overdose epidemic on life expectancy at birth in Canada Canada.ca [Internet]. Canada.ca. 2016 [cited 2021 Jan 7]. Available from: https://www.canada.ca/en/healthcanada/services/substance-use/problematic-prescription-drug-use/opioids/data-surveillance-research/measuringimpact-on-life-expectancy.html

21. Collins AB, Ndoye CD, Arene-Morley D, Marshall BDL. Addressing co-occurring public health emergencies: The importance of naloxone distribution in the era of COVID-19. International Journal of Drug Policy [Internet]. 2020 Sep [cited 2021 Mar 15];83:102872. Available from: https://www.ncbi.nlm.nih.gov/pmc/articles/PMC7373067/

22. Leece P, Orkin A, Shahin R, Steele LS. Can naloxone prescription and overdose training for opioid users work in family practice? Perspectives of family physicians. Canadian family physician Medecin de famille canadien [Internet]. 2015 [cited 2021 Jan 7];61(6):538-43. Available from: https://www.ncbi.nlm.nih.gov/pmc/articles/PMC4463897/

23. Lacroix L, Thurgur L, Orkin AM, Perry JJ, Stiell IG. Emergency physicians' attitudes and perceived barriers to the implementation of take-home naloxone programs in Canadian emergency departments. CJEM [Internet]. 2017 Sep 18 [cited 2021 Jan 7];20(1):46-52. Available from: https://pubmed.ncbi.nlm.nih.gov/28918769/

24. Thorne S, Kirkham SR, O'Flynn-Magee K. The Analytic Challenge in Interpretive Description. International Journal of Qualitative Methods. 2004 Mar;3(1):1-11. Available from: https://doi.org/10.1177\%2F160940690400300101

25. Spinuzzi C. The methodology of participatory design. Technical communication. 2005 May 1;52(2):163-74. Available from: https://repositories.lib.utexas.edu/bitstream/handle/2152/28277/SpinuzziTheMethodologyOfParticipatoryDesign.pdf

26. Hagen P, Collin P, Metcalf A, Nicholas M. Participatory Design of evidence-based online youth mental health promotion, intervention and treatment // A Young and Well Cooperative Research Centre innovative methodologies guide [Internet].; 2012. Available from:

https://researchdirect.westernsydney.edu.au/islandora/object/uws:18814/datastream/PDF/view

27. Gregory J. Scandinavian Approaches to Participatory Design [Internet]. ResearchGate. unknown; 2003 [cited 2021 Jan 7]. Available from:

https://www.researchgate.net/publication/228872045_Scandinavian_Approaches_to_Participatory_Design

28. Steen M, Manschot M, De Koning N. Benefits of Co-design in Service Design Projects [Internet]. International Journal of Dsign. 2011 [cited 2021 Jan 7]. Available from: http://www.ijdesign.org/index.php/IJDesign/article/view/890/346

29. Donetto S, Pierri P, Tsianakas V, Robert G. Experience-based Co-design and Healthcare Improvement: Realizing Participatory Design in the Public Sector [Internet]. ResearchGate. Bloomsbury Publishing; 2015 [cited 2021 Jan 7]. Available from: https://www.researchgate.net/publication/275153597_Experience-based_Codesign_and_Healthcare_Improvement_Realizing_Participatory_Design_in_the_Public_Sector

30. Ferreira B, Conte T, Diniz Junqueira Barbosa S. Eliciting Requirements Using Personas and Empathy Map to Enhance the User Experience [Internet]. IEEE Xplore. 2015 [cited 2020 Sep 4]. p. 80-9. Available from:

Page 17/18 
https://ieeexplore.ieee.org/abstract/document/7328012

31. Marquez JJ, Downey A, Clement R. Walking a Mile in the User's Shoes: Customer Journey Mapping as a Method to Understanding the User Experience [Internet]. ResearchGate. Taylor \& Francis (Routledge); 2015 [cited 2021 Jan 7]. Available from:

https://www.researchgate.net/profile/Joe_Marquez2/publication/288006156_Walking_a_Mile_in_the_User

32. Sellen K, Goso N, Hunt R, Orkin A. Addressing stigma and marginalisation in the design of naloxone packaging to support opiate overdose response. In: Design4Health. Sheffield, UK; 2018.

33. Sellen K, Orkin A. Co-design of a naloxone distribution kit for family practice, emergency departments, and addictions medicine. In: Family Medicine Forum. Toronto, Canada; 2018.

34. Sellen K, Goso N, Hunt R, Strike C, Parsons J, Orkin A. Designing Overdose Education and Naloxone Distribution Kits: co-design with family medicine, emergency department, addictions, and community. PLOSOne. 2021;-(-):-.unpublished work

35. Orkin A, Campbell D, Handford C, Hopkins S, Klaiman M, Leece P. Protocol for a mixed-methods feasibility study for the surviving opioid overdose with naloxone education and resuscitation (SOONER) randomised control trial. [cited 2021 Jan 7]; Available from: https://bmjopen.bmj.com/content/bmjopen/9/11/e029436.full.pdf

36. Antoniou T, Ala-Leppilampi K, Shearer D, Parsons JA, Tadrous M, Gomes T. "Like being put on an ice floe and shoved away": A qualitative study of the impacts of opioid-related policy changes on people who take opioids. International Journal of Drug Policy [Internet]. 2019 Apr [cited 2021 Jan 7];66:15-22. Available from:

https://www.sciencedirect.com/science/article/pii/S0955395919300234

37. Sandelowski M. Theory unmasked: The uses and guises of theory in qualitative research. Research in Nursing and Health [Internet]. 1993;16():213-8. Available from: https://doi.org/10.1002/nur.4770160308

38. Link BG, Phelan J. Stigma power. Social Science \& Medicine [Internet]. 2014 Feb [cited 2021 Jan 7];103:24-32. Available from: https://www.ncbi.nlm.nih.gov/pmc/articles/PMC4451051/39.Bazeley P. Analysing qualitative data: More than 'identifying themes'. Malaysian Journal of Qualitative Research. 2009 Jan;2(2):6-22.

39. Miller W, Crabtree B. The dance of interpretation. In: Crabtree B, Miller W, editors. Doing qualitative research. Thousand Oaks: Sage Publications; 1999. p. 127-143.

40. Parsons JA, Baker NA, Smith-Gorvie T, Hudak PL. To “Get by" or "get help"? A qualitative study of physicians' challenges and dilemmas when patients have limited English proficiency. BMJ Open [Internet]. 2014 Jun 5 [cited 2021 Jan 7];4(6):e004613-3. Available from: https://bmjopen.bmj.com/content/4/6/e004613

41. Dye JF, Schatz IM, Rosenberg BA, Coleman ST. Constant Comparison Method: A Kaleidoscope of Data [Internet]. NSUWorks. 2015 [cited 2021 Jan 7]. Available from: https://nsuworks.nova.edu/tqr/vol4/iss1/8/

42. Fairbairn N, Coffin PO, Walley AY. Naloxone for heroin, prescription opioid, and illicitly made fentanyl overdoses: Challenges and innovations responding to a dynamic epidemic. International Journal of Drug Policy [Internet]. 2017 Aug [cited 2021 Jan 7];46:172-9. Available from: https://www.ncbi.nlm.nih.gov/pmc/articles/PMC5783633/

43. Goffman E. Stigma: notes on the management of spoiled identity. London: Penguin Books; 1990.

44. Link BG, Phelan JC. Conceptualizing Stigma. Annual Review of Sociology. 2001 Aug;27(1):363-85.

45. Lindemann H. Damaged identities, narrative repair. Ithaca: Cornell Univ. Press; 2001. 